affected infants with icterus gravis from rhesus incompatibility may show quite extensive petechiae, and the prognosis in such cases is not good. Capillary naevi should not be confused with skin haemorrhages. They are common, especially around the eyelids, forehead, and occiput, though they may occur elsewhere. Most of them disappear spontaneously.

Haemorrhage from the Lungs.-This is usually a terminal event in pneumonia or septicaemia. Pink frothy fluid may flow from the mouth or nose in an almost continuous stream. Treatment is not likely to be of any avail, but intensive chemotherapy should be tried.

Next article on Emergencies in General Practice.“Ocular Emergencies," by Mr. H. B. Stallard.

Refresher Course Book.-Copies of the second volume of collected articles from the Refresher Course for General Practitioners are still available at $25 \mathrm{~s}$. (postage 1s.) each. The first volume is now sold out.

Clinical Pathology Book.- " Clinical Pathology in General Practice," a collection of 39 articles on clinical pathology that appeared in the Journal as part of the Refresher Course for General Practitioners, is now available, price 21s. (postage 9d.).

Both these volumes are obtainable from the Publishing Manager, B.M.A. House, Tavistock Square, London, W.C.1. or through any bookseller.

\section{THE REGISTRATION OF CANCER IN DENMARK}

BY

Sir ERNEST KENNAWAY, D.M., D.Sc., F.R.S. From the Department of Pathology, St. Bartholomew's Hospital, London

The data collected in Denmark, Norway, Finland, and Iceland should be of great value in the study of cancer. The various Scandinavian peoples, while fully aware of each other's defects, show no great differences in race and religion such as beset similar inquiries in some countries-for example, India. The first three of these countries have Cancer Registration in operation (since 1942 in Denmark, 1952 in Norway, and 1953 in Finland), and in Iceland data from the whole country are collected by Professor Dungal (1955). During my visit to Denmark in June of this year, Dr. Johannes Clemmesen, Director of the Danish Cancer Registry, was preparing for a conference of representatives from all countries which have adopted Cancer Registration, to be held in Copenhagen in the latter part of that month.* The low atmospheric pollution in all these Scandinavian countries should assist in deciding whether this factor plays any part in the causation of cancer.

\section{Denmark}

Denmark lies between the latitudes, roughly, of Newcastle and of Inverness, and hence escapes the long duration of darkness in winter which is an important factor in the northern Scandinavian countries. It has no mountainous and thinly populated districts such as those in Norway, for instance, which are remote from hospitals and facilities for medical treatment. Practically all the country that is not urban is agricultural, and the populations of Copen-

* About $70 \%$ of cases of cancer in England and Wales are now registered under a scheme initiated by the General Register Office, but these are not necessarily representative of the whole " cancer population." hagen, of other urban areas, and of the rural districts are roughly, 1 million, 1 million, and 2 millions. This simple ratio facilitates inquiry into the all-important question of the prevalence of cancer under urban and rural conditions. If the number of deaths from, or registered cases of, any form of cancer in these three classes of area depart widely from a 1:1:2 ratio one has an indication for more exact inquiry. Since modern medical treatment is available to the whole population, the data collected by the Registry should be of great value in seeking for the reason of differences between town and country in the incidence of the various forms of cancer (Clemmesen, 1951a, 1955).

A peculiarity of the national smoking habits is of some interest: some women smoke cigarillos (small cigars weighing about half as much again as a cigarette); I brought back some cigarillos and cigarettes for estimation of their arsenic content.

\section{Copenhagen}

Dr. Clemmesen has an intimate knowledge of Copenhagen, his native city, and is well qualified to judge of the differences in the incidence of cancer of various organs in the different districts, and of the factors, ranging from cosmic radiations to part-time prostitution, which have been suggested in explanation of these differences. He finds that the frequency of cancer of the cervix uteri, and of the lung in males, ranges in inverse proportion to house rent (Clemmesen, 1951b).

In the more modern parts of the city, especially towards the north, one is impressed by the width of the streets, and by the generous areas allotted to squares, museums, and hospitals, and from almost every point one can see trees, in avenues, parks, and gardens. The eastern side of the city abuts on the Baltic, which stretches ten miles to the coast of Sweden. The older parts are of course more densely occupied, and smoke from the railway, factories, and a power station is perceptible, but everywhere the city gives an impression of cleanliness to anyone familiar with the larger cities of Britain. "Smoke papers" were being collected daily at four stations, and these are examined at the Fuel Research Station at Greenwich for degree of blackness, and in Professor Blacklock's department at St. Bartholomew's Hospital for hydrocarbons by Mr. J. M. Campbell, B.Sc., and for arsenic by myself. The four stations are situated, one in the more industrial south-western quarter, two in the older parts of the middle of the city, and one in the northern area, Gentofte, a district of high rents and large gardens. We had noted consistent differences between the smoke papers from the four stations, of which we in London knew nothing but their names, and it was interesting to note, when one visited the stations, that these differences were very much what one might expect from the general character of the localities. One may perhaps mention, to illustrate the pleasant character of Gentofte, that just as the funnel projecting from a window to collect suspended matter came into view one heard, for the first time this year, the note of a willow-wren, a bird whose song in England had been discouraged by the cold spring.

Mr. D. S. Teglbjaerg, of the Institute of Hygiene, collected for us from a neglected window-ledge about $50 \mathrm{~g}$. of dust which we have brought home for analysis, and some similar material was obtained for us at Professor J. Engelbreth-Holm's Institute of Pathology.

Domestic heating is carried out chiefly by coke burned in stoves, or in the central water-heating plants of flats; the coke is produced in the local gasworks, from coal imported from Britain, Poland, and Germany, and the gas is consumed for cooking and in gas fires. Small amounts of coal are used for starting coke fires. In the richer districts, such as Gentofte, the central heating of individual houses is effected by oil-fired boilers, the oil being imported from the U.S.A. or South America. One power station in Copenhagen is diesel-engined. Since the last war there has been a tendency to conserve peat, which is the only indigenous fuel and has been used only in wartime. 
Dr. Clemmesen took us to a meeting of the committee of the Danish Medical Association that is concerned with lung cancer problems under the chairmanship of the Professor of Hygiene, Dr. Bonnevie, and I was able to say something in support of a proposed inquiry into smoking habits in Denmark. Dr. Clemmesen hopes to associate with this investigation a study of the histological types of cancer of the lung, such as has been carried out by Professor Kreyberg in Norway, and he estimates tentatively that the occurrence of different types in the same tumour causes serious difficulty in classification only in about $5 \%$ of cases.

\section{The Danish Cancer Registry}

The Danish Cancer Registry is conducted for the purposes of research on a purely voluntary basis with support from the public health authorities, who grant housing accommodation, and from the State Office for Statistics, which gives facilities for mechanical (Hollerith) tabulation.

Dr. Clemmesen describes the origin of the Registry as follows :

"In 1937 Kennaway and Kennaway made a review synthesizing experimental and statistical evidence on carcinogenesis. It appeared from their paper-reviewed in Hospitalstidende 1938 - that mortality statistics from England and Wales had revealed differences in mortality from cancer between various social classes" (the data in question were those of the Registrar-General, London), "and it lay near to examine whether corresponding results could be produced on the basis of Danish death certificates. Contrary to the expectations of the author, subsequent studies on cancer mortality among Danish breadwinners of various occupations confirmed that also in Denmark differences could be demonstrated between certain occupational groups, and between the capital, provincial towns, and rural areas. It was clear, however, that, inspiring as such mortality studies may be, they cannot compare in accuracy with studies on cancer morbidity, primarily because progress in therapy will tend to make mortality statistics increasingly inadequate as a measure of the real incidence of this group of diseases, and it was therefore suggested by the author that a continuous registration should be made of all cases of cancer in the Kingdom of Denmark, based on reports from pathologists and surgeons, supplemented with the information available from death certificates."

The Registry was set up on May 5, 1942, by a committee of the National Cancer League, with Professor J. EngelbrethHolm as chairman. Dr. Johannes Clemmesen was appointed Director, and his staff now consists of a half-time actuary. Mr. Arne Nielsen, and five clerks and typists.

"At the opening of the Registry it had been decided to collect information on all cases of cancer admitted to hospital or treated as out-patients as well as information on all autopsies performed on patients suffering from malignant disease. Under the assumption-which in Denmark is quite safe-that no patient will be cured of malignant disease without visiting a hospital, it was decided not to approach practising physicians for information on patients, since it was realized that it would hardly be possible in this way to obtain better information than that already available from death certificates, which through the courtesy of the National Health Service had been made accessible to the Cancer Registry."

"Since in Denmark cancer is not a reportable disease, all hospital services were approached and agreed to notify cases of malignant disease to the Registry at a token fee of 1 krone for each, as a symbol that notifications would be appreciated and not just shelved."

The great majority of hospitals are public and practically free of charge; the number of private clinics is negligible. About $85 \%$ of the population are members of the Health Insurance and are admitted to hospitals free of charge, while the remaining $15 \%$ are charged about $3 \mathrm{~s}$. a day.

The Registry now possesses data for about 100,000 cases of cancer. The oldest living person on the records is aged
105 ; in earlier life he was operated upon for cancer of the skin. "Danish death certificates are legal documents practically always issued or verified by doctors."* Cancer of the cervix is in Denmark almost always treated in hospital, while "the diagnosis of gastric carcinoma is often made without the use of modern diagnostic methods." Fortyeight per cent. of deaths from cancer take place in hospitals. The number of cases notified yearly is about 10,000 , and of deaths about 8,000 . The difference is due in part to cases of cancer of the cervix and of the skin, and a large proportion of these will be on the records of the three radium hospitals which the National Cancer League itself provided, at which 2,800 cases of cancer are treated yearly. Every year several hundred cases appear on death certificates which had not been notified by the hospitals concerned, and these cases are made the subject of inquiry.

Dr. Clemmesen had always been opposed to the predominant use of the records for the comparison in detail of different methods of treatment, as this activity tends to swamp all others; the register is intended to serve as a key for investigators to the raw material available upon many aspects of cancer.

Dr. Clemmesen took much trouble in making our visit useful and enjoyable in every way. We are indebted also to Dr. J. Engelbreth-Holm, Professor of Pathology, to Mr. Arne Nielsen, of the Cancer Registry, and to Dr. Bonnevie and Mr. D. S. Teglbjaerg, of the Institute of Hygiene, for help and information upon various matters.

\section{Some Notes of Travel}

Dr. Sjölin took us in his car, with Dr. Clemmesen, to Trelleborg, a very strong Viking fortress dating from about A.D. 1000. Each wooden house could provide quarters for the crew of a Viking longship. One of these houses has been reconstructed and shows the stone-paved hearth in the middle of the great hall; the smoke escaped through an opening in the roof. This arrangement, familiar to readers of the Icelandic sagas, persisted to the present day in farmhouses in Iceland (Blacklock et al., 1954), of which Professor Niels Dungal, of Reykjavik, has given a first-hand description; he obtained for us soot from the walls of one of these houses, which was found to contain $3: 4$-benzpyrene.

On the way back from Trelleborg to Copenhagen we were entertained at tea by Dr. Claus M. Plum and his wife, who superintend a colony of epileptic children, among them some Eskimos from Greenland. If one reads the Heimskringla Saga of Snorre Sturlason, $\dagger$ with its stories reminiscent of the Old Testament-for example, Deuteronomy ii. $32-5$; iii. 5-7 ; Judges xx. 48 ; II Samuel xii. 31 - of merciless slaughter and plunder, one may reflect that, to the men of Trelleborg, this transport of children of another race over 2,000 miles for their own good would have been unintelligible.

In Copenhagen it is instructive to go to a cafeteria, of the same class as a Lyons restaurant in London, and see what items are in most demand. One can there obtain alcoholic drinks in bottles, but the commonest drink, as in Finland and Iceland, seems to be milk. A favourite dish is Frankfurters, dyed an intense scarlet, together with a very attractive mixture of potato, apple, and onion reminiscent of the squab pie of Devonshire. Sandwiches take the "open" form, of which one restaurant claims to provide 100 varieties.

\section{REFERENCES}

Blacklock, J. W. S., Kennaway, E. L., Lewis. G. M., and Urquhart, M. E. (1954). Brit. J., Cancer, 8. 40.

Clemmesen, J. (1951a). Acta Un. int. Cancr., 7, 24

- (1951b). J. nat. Cancer Inst., 12, 1.

(1955). Dan. med. Bull., p. 124.

Dungal, N. (1955). Ann. roy. Coll. Surg. Engl., 16. 211 2. 101 .

* In the rural areas only, a few death certificates, amounting to about $0.1 \%$ of the whole, are issued by coroners.

† A translation is available in " Everyman's Library." 